\title{
The impact of metformin and salinomycin on transforming growth factor $\beta$-induced epithelial-to-mesenchymal transition in non-small cell lung cancer cell lines
}

\author{
STEFAN KOECK $^{1}$, ARNO AMANN ${ }^{1}$, JULIA M. HUBER ${ }^{1}$, GABRIELE GAMERITH ${ }^{1}$, \\ WOLFGANG HILBE ${ }^{1,2}$ and HEINZ ZWIERZINA ${ }^{1}$ \\ ${ }^{1}$ Department of Internal Medicine V, Medical University of Innsbruck, Innsbruck, Tyrol 6020; \\ ${ }^{2}$ Department of Internal Medicine I, Wilhelminenspital, Vienna 1160, Austria \\ Received January 13, 2015; Accepted February 16, 2016
}

DOI: $10.3892 / 01.2016 .4323$

\begin{abstract}
The epithelial-to-mesenchymal transition (EMT) is highly involved in the development of metastases. EMT transforms epithelial carcinoma cells into mesenchymal-like cells, characterized by increased cell migration and invasiveness. Transforming growth factor $\beta$ (TGF $\beta$ ) appears to be crucial in this process. Metformin and salinomycin have demonstrated an EMT inhibitory effect. The current experiments indicate that these substances specifically inhibit TGF $\beta$-induced EMT in non-small cell lung cancer (NSCLC) cell lines. The NSCLC cell lines A549 and HCC4006 were stimulated with TGF $\beta$ for $48 \mathrm{~h}$ to induce EMT. Metformin or salinomycin was added simultaneously with TGF $\beta$ to inhibit TGF $\beta$-induced EMT. Western blot analyses of E-cadherin and vimentin were performed to detect changes in EMT marker expression, and a wound healing assay was conducted to determine the potential effects on cell migration. The effects of the two drugs on cell viability were also investigated using MTS tetrazolium dye assays. The results revealed that cells undergoing EMT by application of TGF $\beta$ exhibited a downregulation of E-cadherin and an upregulation of vimentin protein expression on western blot analyses, and an increased capacity for cell migration. Simultaneous application of TGF $\beta$ and metformin specifically inhibited EMT and increased E-cadherin expression. At the higher dose tested, salinomycin also inhibited EMT, despite an increase in vimentin expression in the two cell lines. Furthermore, metformin and salinomycin, at the two concentrations tested, inhibited cell migration. These findings demonstrate that metformin and salinomycin are able to block EMT and inhibit
\end{abstract}

Correspondence to: Dr Stefan Koeck, Department of Internal Medicine V, Medical University of Innsbruck, Anichstraße 35, Innsbruck, Tyrol 6020, Austria

E-mail: stefan.koeck@i-med.ac.at

Key words: epithelial marker, epithelial-to-mesenchymal transition, metformin, migration, non-small cell lung cancer, salinomycin, transforming growth factor $\beta$
EMT-induced cell migration. Thus, these two substances are novel EMT inhibiting drugs that have the potential to specifically control EMT and metastatic spread in NSCLC.

\section{Introduction}

The epithelial-to-mesenchymal transition (EMT) is a central molecular mechanism that is known to be involved in a wide range of physiological and pathophysiological processes. In cancer, EMT is crucial in the development of metastases (1) as it induces the transformation of carcinoma cells into mesenchymal cells. This process is accompanied by changes in cell morphology and structure, altered signaling pathways, and increased cell migration and invasiveness (2).

EMT is associated with structural changes, which comprise downregulation of epithelial markers (such as E-cadherin) and upregulation of mesenchymal markers (such as vimentin, N-cadherin or smooth-muscle actin). Transcription factors, including Twist, Snaill and Slug, are upregulated in parallel, reflecting the implementation of the epithelial-to-mesenchymal transition $(3,4)$. Among the various signaling pathways involved in EMT and metastatic spread, the transforming growth factor $\beta$ (TGF $\beta$ ) pathway has been demonstrated to serve a key role (5). It has been established that TGF $\beta$ activates mesenchymal transformation, and TGF $\beta$ has also been identified as a crucial cytokine involved in tumor-related features, such as cell invasion and intercellular communication within the cancer microenvironment. Among other effects, TGF $\beta$ activates the SMAD2/3 cascade, causing a subsequent upregulation of transcription factors that finally results in mesenchymal transformation $(4,6)$. Due to its involvement in the complex tumor-stroma interaction, EMT may be a central target for novel anti-metastatic therapeutic approaches.

Recent studies have demonstrated that cancer cell growth is affected by the antidiabetic agent metformin (7), which has been shown to reduce the risk of cancer in patients with diabetes type 2 (8). A number of pathways may represent potential targets for the anticancer effects of metformin (9). Recent investigation has indicated that metformin is able to inhibit EMT (10). Additionally, in endometrial cancer cell lines, metformin is able to reduce the potential for cell migration (11). 
Salinomycin is a polyether ionophore that was originally used as an antibiotic to prevent infectious diseases in poultries (12). Recently, cytotoxic effects of this drug on human neoplastic cells have been demonstrated in various types of cancer (13-16). These cytotoxic effects are partially caused by the killing of human cancer stem cells $(13,14)$ based on various molecular interactions, including the downregulation of the expression of oncogenes such as MYC and ERG (17). In addition to its effect on stem cells, salinomycin inhibits cancer cell migration (17).

The experimental approach used in the present study, using NSCLC cell lines, is based on the hypothesis that TGF $\beta$ is able to induce EMT in NSCLC cell lines, causing a phenotypical transformation of epithelial cancer cells into EMT-transformed mesenchymal-like cells, with a subsequent increase in migration ability. Furthermore, we hypothesized that the simultaneous treatment of NSCLC cells with TGF $\beta$ and metformin or salinomycin may inhibit EMT. Western blot analyses were performed to detect changes in epithelial and mesenchymal markers following treatment of NSCLC cell lines with TGF $\beta$ in combination with metformin or salinomycin. A cell migration assay was conducted to analyze the invasive capacity of transformed vs. non-transformed cells, and an MTS assay was performed to examine relevant sublethal doses of metformin and salinomycin for these experiments.

\section{Materials and methods}

Cell lines \& reagents. The A549 human NSCLC cell line (\#ACC-107) was purchased from Deutsche Sammlung von Mikroorganismen und Zellkulturen GmbH (DSMZ; Braunschweig, Germany), and the HCC4006 human NSCLC cell line (\#CRL-2871) was purchased from the American Type Culture Collection (ATCC-LGC; Wesel, Germany). The two cell lines were cultured in Dulbecco's modified Eagle's medium (DMEM) with low glucose (GE Healthcare Life Sciences, Vienna, Austria), supplemented with $10 \%$ fetal calf serum (FCS; Sigma-Aldrich, Munich, Germany) and $100 \mathrm{U} / \mathrm{ml}$ penicillin, $100 \mu \mathrm{g} / \mathrm{ml}$ streptomycin and $2 \mathrm{mM}$ L-glutamine (PAA Laboratories; GE Healthcare Life Sciences). The cells were cultivated in cell culture flasks (Falcon ${ }^{\circledR}$; Becton-Dickinson Austria $\mathrm{GmbH}$, Schwechat, Austria) at $37^{\circ} \mathrm{C}$ in an atmosphere of $5 \% \mathrm{CO}_{2}$ until the desired cell confluence for further experiments was reached.

TGF $\beta$ was obtained from R\&D Systems (Vienna, Austria) and prepared according to the manufacturer's recommendation. Metformin and salinomycin were obtained from Sigma-Aldrich. The two drugs were dissolved in sterile water and stored at $-20^{\circ} \mathrm{C}$ until use as aliquots of $100 \mathrm{mM}$ (metformin) and $1 \mathrm{mM}$ (salinomycin).

EMT induction and inhibition. Cells were seeded at a density of $60 \%$ (A549) and 80\% (HCC4006) per well to obtain equal cell densities after $48 \mathrm{~h}$. Following incubation overnight, the cells were stimulated with TGF $\beta$ (10 ng/ml) in starving medium (1\% FCS) and subsequently incubated for $48 \mathrm{~h}$ until protein extraction for western blot analyses. For scratch assays, TGF $\beta$ stimulation $(10 \mathrm{ng} / \mathrm{ml})$ for $48 \mathrm{~h}$ was performed subsequent to scratching.

To attempt to induce EMT inhibition, metformin at concentrations of $0.1 \mathrm{mM}$ and $1 \mathrm{mM}$ for A549 cells, and $1 \mathrm{mM}$ and
$10 \mathrm{mM}$ for HCC4006 cells, and salinomycin at concentrations of $1 \mu \mathrm{M}$ and $0.1 \mu \mathrm{M}$ for both cell lines, were added alone or in combination with TGF $\beta$ for $48 \mathrm{~h}$ for western blot analyses and scratch assays.

Determination of metabolic activity. For growth inhibition studies, an MTS assay was used (CellTiter 96 ${ }^{\circledR}$ AQueous Non-Radioactive Cell Proliferation Assay; Promega, Madison, WI, USA). Cells were seeded at a concentration of 5,000 cells/well in a 96-well microplate and incubated overnight at $37^{\circ} \mathrm{C}$ and in an atmosphere of $5 \% \mathrm{CO}_{2}$. Fresh medium and substances in the appropriate concentrations were added and incubated in the same conditions again for $48 \mathrm{~h}$. Subsequently, $10 \mu \mathrm{l}$ MTS substrate solution for each $100 \mu$ l culture medium per well was added. The microplates were incubated for $4 \mathrm{~h}$ at $37^{\circ} \mathrm{C}$ and with $5 \% \mathrm{CO}_{2}$, before optical density was measured at $490 \mathrm{~nm}$ with a microplate reader (Tecan Infinite ${ }^{\circledR}$ M200 PRO; Tecan Group, Männerdorf, Switzerland). Untreated cells were used as the control, adding the same amount of drug-free solvent (distilled water) as in the highest drug concentration.

Protein extraction and western blot. For protein extraction, cells were cultivated in 12-well plates at densities of 50,000 cells/well (A549) and 70,000 cells/well (HCC4006) to obtain equal cell densities after $48 \mathrm{~h}$. After cultivation with the substances as mentioned above, medium was removed from the culture plates. Cells were then rinsed three times with phosphate-buffered saline and incubated for $2 \mathrm{~h}$ on ice with $150 \mu \mathrm{l}$ radioimmunoprecipitation assay buffer containing a protease inhibitor cocktail (working concentration, 1\%; \#P8340; Sigma-Aldrich). Lysate was centrifuged at $15,000 \mathrm{xg}$ for $10 \mathrm{~min}$ at $4^{\circ} \mathrm{C}$. The total protein concentration was determined by using a Pierce ${ }^{\mathrm{TM}}$ bicinchoninic acid assay Kit (Thermo Fisher Scientific, Carlsbad, CA, USA) using bovine serum albumin as a standard. Proteins $(30 \mu \mathrm{g})$ were electrophoretically separated and blotted according to standard procedures. Briefly, protein lysate (30 $\mu \mathrm{l}$ containing $30 \mu \mathrm{g}$ of total protein) and $6 \mu \mathrm{l} 6 \mathrm{X}$ Laemmli buffer (Bio-Rad Laboratories, Inc., Munich, Germany) were mixed and heated at $95^{\circ} \mathrm{C}$ for $5 \mathrm{~min}$. Proteins were separated using a $10 \%$ sodium dodecyl sulfate (SDS)-polyacrylamide gel electrophoresis separation gel at $180 \mathrm{~V}$ for $1 \mathrm{~h}$ (running buffer consisted of $1.44 \%$ glycine, $0.3 \%$ Tris and $0.1 \%$ SDS). For western blot analysis, a nylon membrane (Amersham HybondTM-N+; GE Healthcare Life Sciences, Little Chalfont, UK) was used and proteins were transferred with transfer buffer (Novex Tris-Glycine; Invitrogen; Thermo Fisher Scientific) at $25 \mathrm{~V}$ for $90 \mathrm{~min}$ at $6^{\circ} \mathrm{C}$. Subsequent to blotting, membranes were washed with washing buffer $(0.9 \% \mathrm{NaCl}, 0.6 \%$ Tris, $0.1 \%$ Tween) and were then blocked for $1 \mathrm{~h}$ at room temperature with a blocking buffer (washing buffer containing 5\% milk powder).

Membranes were incubated with primary antibodies in blocking buffer at $6^{\circ} \mathrm{C}$ overnight. Subsequently, membranes were washed with washing buffer and incubated with the secondary antibody in blocking buffer at room temperature for $1 \mathrm{~h}$. After final washing, membranes were treated with ECL Select western blotting detection reagent (GE Healthcare). Primary antibodies against human GAPDH (polyclonal rabbit; \#G9545; Sigma-Aldrich), E-cadherin (monoclonal rabbit IgG; \#3195) and vimentin (monoclonal rabbit IgG; \#5741), 
a horseradish peroxidase (HRP)-linked goat anti-rabbit IgG secondary antibody (\#7074) and a HRP-linked goat anti-biotin antibody (\#7075) (all from Cell Signaling Technology, Cambridge, UK) were used. Primary antibodies were used at a concentration of 1:2,000, whilst secondary antibody and biotinylated protein ladder antibody were diluted 1:10,000. Blots were exposed and documented using the Molecular Imager Gel Doc XR Systems (Bio-Rad Laboratories, Inc., Boston, MA, USA). Unstimulated and untreated cells were used as the negative control, whereas TGF $\beta$-stimulated and untreated cells were used as the positive control.

Scratch assay. The scratch assay was performed according to a modified version of the method described by Liang et al (18). Cells were seeded in 12-well culture plates with low-glucose DMEM supplemented with $10 \%$ FCS and cultivated until subconfluence. Subsequently, cells were starved in standard low-glucose DMEM with reduced FCS (1\%) for $24 \mathrm{~h}$. On the following day, the cell monolayer was scraped with a $200 \mu \mathrm{l}$ pipette tip held at an angle of $45^{\circ}$. Culture plates were then washed twice with low-glucose DMEM containing $1 \%$ FCS, and $500 \mu \mathrm{l}$ of this medium was then added per well.

Following this procedure, the first image of each well was captured. According to the current experimental approach, cells were treated with or without TGF $\beta$, metformin and/or salinomycin in starving medium as described, and were incubated for $48 \mathrm{~h}$. Following this incubation, the second images were taken from the exact same location as the first picture for each well.

The free area of the scratch of each picture was measured using ImageJ (v1.44; National Institutes of Health, Bethesda, MD, USA). The first and second images of each well were compared and the difference of the free area was calculated. Unstimulated and untreated cells were used as the negative control, whereas TGF $\beta$-stimulated and untreated cells were used as the positive control.

Statistical analysis. For the dose-response curves and the quantitative analyses of the scratch assays, the mean value and the standard error of the mean are presented. The data were analyzed by the Mann-Whitney $\mathrm{U}$ test and $\mathrm{P}<0.05$ was considered to indicate a statistically significant difference.

\section{Results}

Determination of drug concentration. The MTS assay was performed to determine the drug concentration of metformin and salinomycin for use in the western blot and migration analyses. Growth inhibition is expressed as the percentage of the absorbance values of the untreated control group. The two cell lines yielded a concentration-dependent dose-response curve. Two concentrations that produced $>70 \%$ growth inhibition were selected for further experiments to guarantee the use of sublethal doses. For metformin, $0.1 \mathrm{mM}$ and $1 \mathrm{mM}$ concentrations were used for the A549 cell line (Fig. 1A), and 1 and $10 \mathrm{mM}$ were used for the HCC4006 cells (Fig. 1B). For salinomycin, $0.1 \mu \mathrm{M}$ and $1 \mu \mathrm{M}$ were selected as the concentrations for further experiments for both cell lines (Fig. 1C and D).

Expression of EMT markers. Western blot analyses were performed to analyze the expression of EMT-specific proteins.
E-cadherin expression represents an epithelial phenotype while vimentin was chosen as an indicator for a mesenchymal phenotype (3). Unstimulated cells with or without the higher dose of metformin or salinomycin treatment for $48 \mathrm{~h}$ were compared to TGF $\beta$-stimulated cells that were simultaneously incubated with metformin or salinomycin for $48 \mathrm{~h}$.

In untreated A549 cells, strong E-cadherin expression was detected, whereas vimentin was barely expressed. The application of $1 \mathrm{mM}$ metformin or $1 \mu \mathrm{M}$ salinomycin caused no modification in E-cadherin expression, while a slight downregulation of vimentin in salinomycin treated cells was observed (Fig. 2A).

In TGF $\beta$-stimulated A549 cells, a downregulation of E-cadherin was detected. Stimulated cells that were treated with $1 \mathrm{mM}$ metformin exhibited marked upregulation of E-cadherin expression, and slight vimentin upregulation compared with untreated TGF $\beta$-stimulated cells (Fig. 2A). Treatment of TGF $\beta$-stimulated A549 cells with $0.1 \mathrm{mM}$ metformin induced a slight upregulation of E-cadherin and vimentin. TGF $\beta$-stimulated A549 cells treated with $1 \mu \mathrm{M}$ salinomycin demonstrated an increase in E-cadherin expression compared with untreated TGF $\beta$-stimulated cells. In addition, the expression of vimentin was also upregulated. The addition of $0.1 \mu \mathrm{M}$ salinomycin led to a marginal increase in E-cadherin and vimentin expression in comparison to untreated TGF $\beta$-stimulated A549 cells (Fig. 2A).

Untreated and unstimulated HCC4006 cells exhibited strong expression of E-cadherin, while vimentin was weakly expressed. Treatment with $10 \mathrm{mM}$ metformin caused no distinct alteration of the expression of E-cadherin and vimentin. The application of $1 \mu \mathrm{M}$ salinomycin decreased the E-cadherin expression, but marginally enhanced vimentin expression (Fig. 2B).

Stimulation of HCC4006 cells with TGF $\beta$ resulted in an upregulation of vimentin; however, no difference in E-cadherin expression in comparison to untreated cells was observed (Fig. 2B). Treatment of TGF $\beta$-stimulated cells with $10 \mathrm{mM}$ metformin had no effect on E-cadherin expression, but caused a downregulation of vimentin compared to untreated TGF $\beta$-stimulated cells. Application of $1 \mathrm{mM}$ metformin led to a marginal upregulation of vimentin in comparison to untreated TGF $\beta$-stimulated cells (Fig. 2B). Treatment of TGF $\beta$-stimulated HCC4006 cells with $1 \mu \mathrm{M}$ salinomycin resulted in an enhancement of vimentin expression and an unaffected E-cadherin status. Application of $0.1 \mu \mathrm{M}$ salinomycin caused TGF $\beta$-stimulated cells to downregulate their vimentin expression to the level of untreated cells (Fig. 2B).

Inhibition of EMT mediated cell migration. Scratch assays were performed to analyze the functional effects of EMT and its possible inhibition. Untreated and unstimulated (control) A549 cells barely migrated into the unoccupied area of the scratch. Unstimulated cells treated with $1 \mu \mathrm{M}$ salinomycin demonstrated a similar migration rate to the control $(\mathrm{P}=0.786)$, whereas treatment with $1 \mathrm{mM}$ metformin resulted in a slight but significant $(\mathrm{P}=0.036)$ inhibition of migration (Figs. 3 and 4A).

In contrast to unstimulated cells, TGF $\beta$-stimulated A549 cells exhibited a high migration rate and the scratch area was significantly reduced to $53 \%$ of the control group $(\mathrm{P}=0.004$; Figs. 3 and $4 \mathrm{~A})$. TGF $\beta$-stimulated cells that were treated 
A

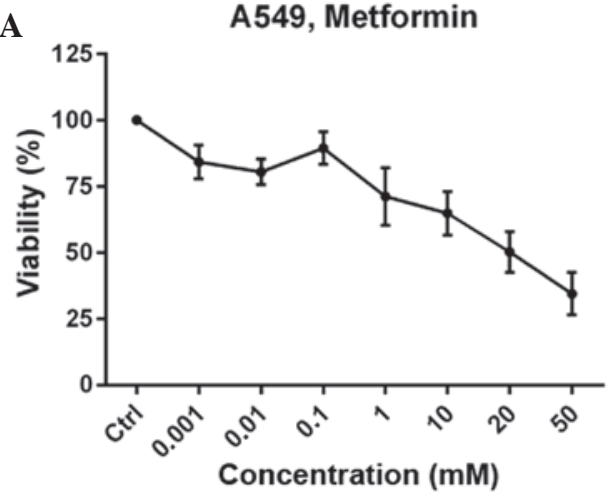

C

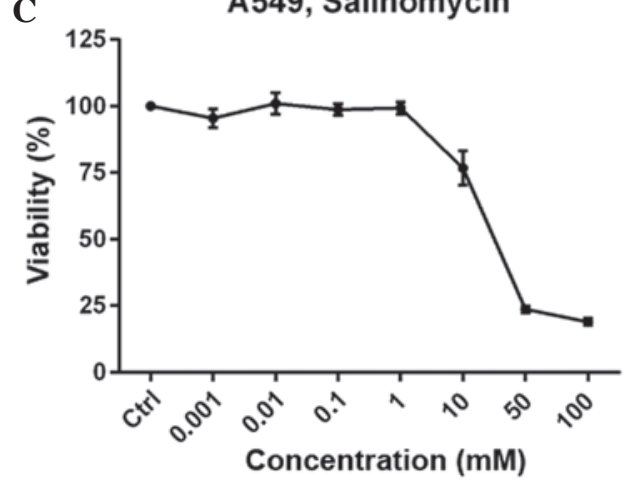

B

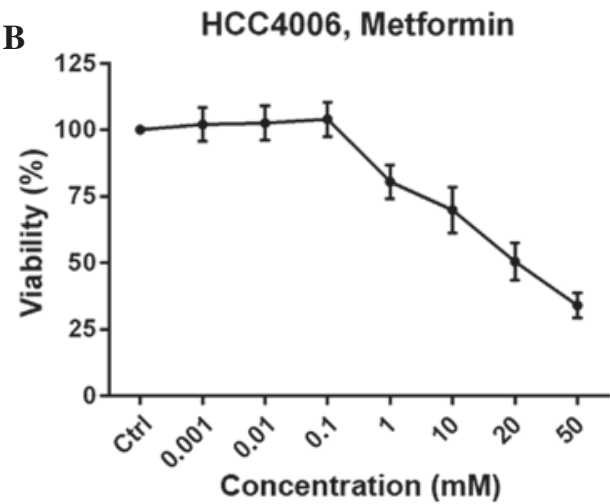

D

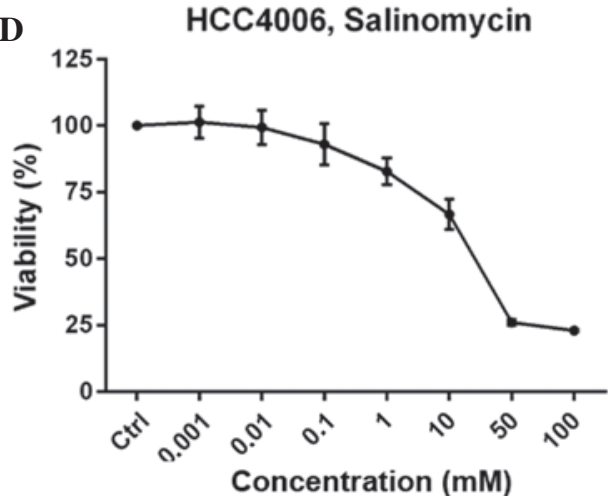

Figure 1. Dose-response curves of metformin and salinomycin. (A and C) A549 and (B and D) HCC4006 cells were treated with (A and B) metformin or $(\mathrm{C}$ and D) salinomycin for $48 \mathrm{~h}$. Metformin was applied in concentrations $\leq 50 \mathrm{mM}$ and salinomycin in concentrations $\leq 100 \mu \mathrm{M}$. Values were compared to untreated cells (Ctrl). The values of untreated cells were assumed to represent $100 \%$ metabolic activity. All points represent the mean value and error bars represent standard error of the mean.

A

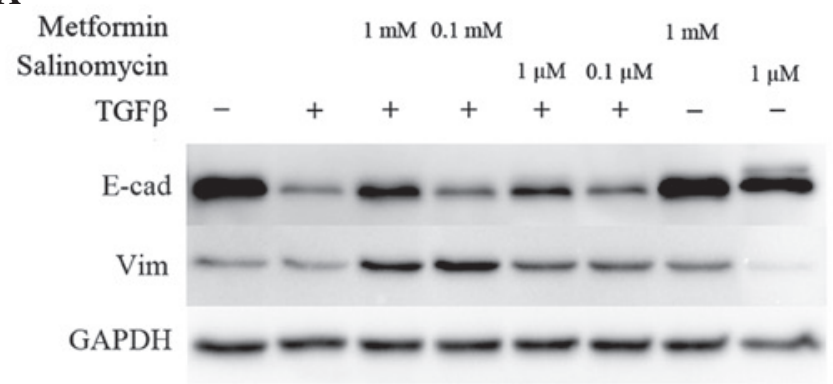

B

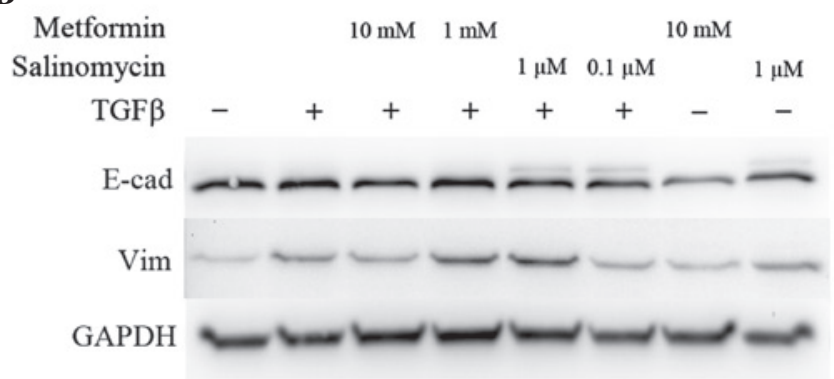

Figure 2. EMT marker expression. Analysis of EMT inhibition in (A) A549 and (B) HCC4006 cells by western blotting. Cells were treated for 48 h with TGF $\beta$ $(10 \mathrm{ng} / \mathrm{ml})$ alone, or TGF $\beta(10 \mathrm{ng} / \mathrm{ml})$ plus metformin or salinomycin in two different concentrations. Protein expression in the two cell lines was compared with completely untreated cells or cells treated with metformin or salinomycin only. E-cadherin expression was used as a marker of the epithelial phenotype, whilst the mesenchymal marker was vimentin. GAPDH was used as a loading control. EMT, epithelial-to-mesenchymal transition; TGF $\beta$, transforming growth factor $\beta$.

simultaneously with metformin had a strongly reduced migration rate compared with untreated TGF $\beta$-stimulated cells. Treatment with $1 \mathrm{mM}$ metformin induced complete inhibition of migration $(\mathrm{P}=0.024)$, whilst $0.1 \mathrm{mM}$ metformin led to a slight but non-significant reduction ( $\mathrm{P}=0.905$; Fig. 4A). Treatment with the two concentrations of salinomycin, 1 and $0.1 \mu \mathrm{M}$, also resulted in a non-significant reduction of migration compared with untreated TGF $\beta$-stimulated cells $(1 \mu \mathrm{M}$, $\mathrm{P}=0.381 ; 0.1 \mu \mathrm{M}, \mathrm{P}=0.167$; Figs. 3 and 4A). In A549 cells treated with $1 \mu \mathrm{M}$ salinomycin, $95 \%$ of the scratched area, relative to the control group, remained free of cells, whilst $0.1 \mu \mathrm{M}$ salinomycin resulted in a free area of $81 \%$.
Untreated and unstimulated HCC4006 cells exhibited slight migratory activity (Fig. 4B). However, treatment of unstimulated cells with $10 \mathrm{mM}$ metformin induced a nearly complete inhibition of migration $(\mathrm{P}=0.048)$, with an increase of the free area to $182 \%$ of the control (Fig. 4B). When unstimulated HCC4006 cells were treated with $1 \mu \mathrm{M}$ salinomycin, $54 \%$ of the scratched area remained free relative to the control group ( $\mathrm{P}=0.167$; Fig. 4B).

Migration increased significantly under TGF $\beta$ stimulation $(\mathrm{P}=0.004)$, with the scratched area free from migrated cells decreasing to $16 \%$ of the control area (Fig. 4B). HCC4006 cells that were simultaneously treated with TGF $\beta$ and $10 \mathrm{mM}$ 


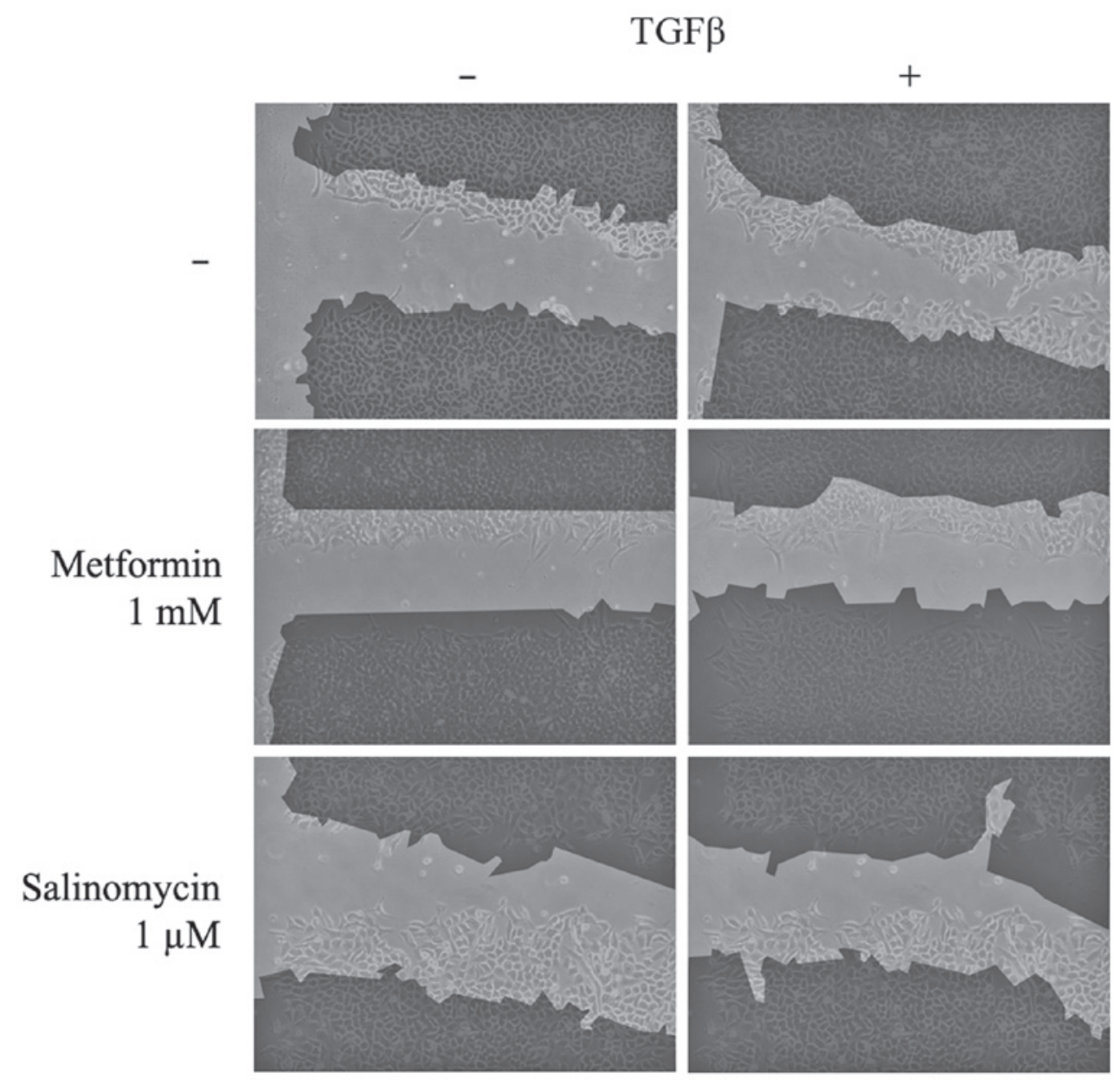

Figure 3. Representative images of the scratch assay conducted on the A549 cell line after $48 \mathrm{~h}$. Images were captured at 0 and $48 \mathrm{~h}$ after scratching. The dark area represents the cell monolayer at the beginning of the experiment. TGF $\beta$, transforming growth factor $\beta$.

A

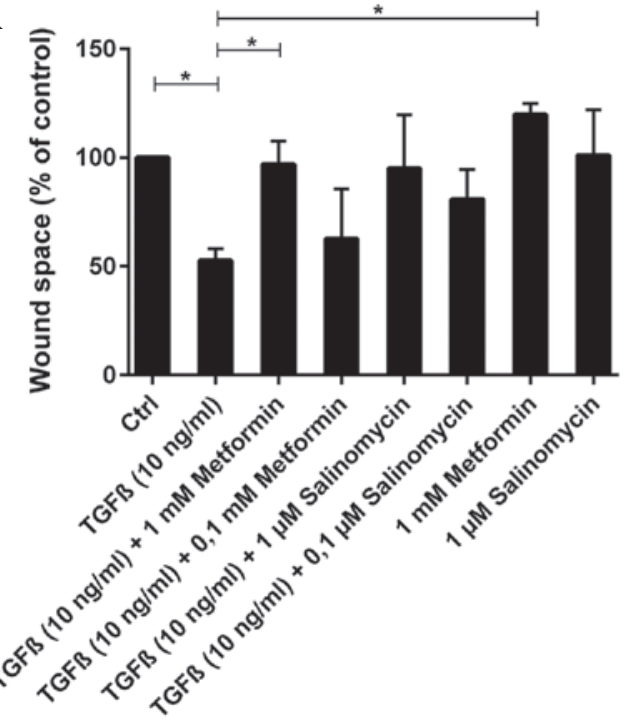

B

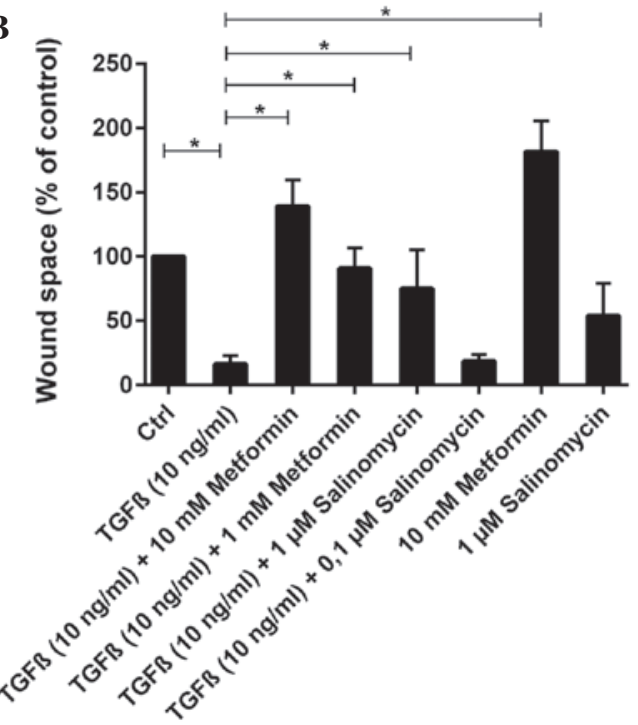

Figure 4. Quantification of the scratch assay experiments on (A) A549 and (B) HCC4006 cells. Quantification was performed using ImageJ. Wound area after $48 \mathrm{~h}$ was measured and subtracted from the wound area at the beginning of the experiment. Results are shown relative to untreated cells (Ctrl; $100 \%)$. All bars show the mean value and error bars represent standard error of the mean. ${ }^{*} \mathrm{P}<0.05$. TGF $\beta$, transforming growth factor $\beta$.

metformin exhibited a significant reduction in migration (Fig. 4B), with the free area reaching $139 \%$ relative to the control group ( $\mathrm{P}=0.036$, compared to $\mathrm{TGF} \beta$ stimulated cells).
The addition of $1 \mathrm{mM}$ metformin to TGF $\beta$-stimulated cells also caused a significant decrease in migration compared with untreated TGF $\beta$-stimulated cells ( $\mathrm{P}=0.036$; Fig. 4B). Addition 
of $1 \mu \mathrm{M}$ salinomycin to unstimulated cells caused a moderate migration inhibition, with $75 \%$ of the scratch remaining free $(\mathrm{P}=0.071$; Fig. 4B). Treatment of TGF $\beta$-stimulated cells with $0.1 \mu \mathrm{M}$ salinomycin did not effect a decrease of migration compared with untreated TGF $\beta$-stimulated cells, and $18 \%$ of the scratched area remained free from migrated cells $(\mathrm{P}=0.786)$.

\section{Discussion}

EMT is a crucial mechanism in the process of metastatic tumor spread. Invasiveness and migration in cancer cells are essential requirements for metastatic growth and may be modified by altering the cellular mechanisms that are regulated by EMT $(19,20)$. The TGF $\beta$-triggered signaling cascade reflects a critical pathway for EMT induction in a number of pathophysiological processes, including lung and myocardial fibrosis $(21,22)$ or cancer growth $(23)$. The crucial role of EMT has recently been identified to in the context of the mechanism of metastatic tumour spread (24). Therefore, EMT pathways represent potential new targets for inhibition of tumor progression. As metformin and salinomycin have been previously demonstrated to inhibit EMT $(10,16)$, these substances were selected for investigation in the current in vitro studies. Two different epithelial NSCLC cell lines, A549 and HCC4006, were used for the investigations.

The results demonstrated that metformin is able to inhibit TGF $\beta$-related EMT in A549 and HCC4006 cells, resulting in a persisting epithelial phenotype and reduced cell migration. Furthermore, these data provide evidence that metformin inhibits EMT when used at sublethal doses, suggesting that it inhibits cellular signalling pathways rather than killing EMT transformed cells.

Metformin also inhibits cell migration in differentiated epithelial cancer cells, as indicated by the decreased cell migration observed in non-EMT transformed cells following the application of metformin. The effect of metformin on non-EMT transformed cells is observed more distinctly in HCC4006 cells than in A549 cells. While recent publications provide evidence for the EMT-inhibitory potential of metformin $(10,25,26)$, the current data also demonstrate, for the first time, the metformin-dependent inhibition of cell migration in differentiated epithelial cancer cells.

In the current study, salinomycin was seen to inhibit the EMT-inducing effect of TGF $\beta$ when used at the lower dose, while the higher dose further enhanced the mesenchymal phenotype in HCC4006 cells. In A549 and HCC4006 cells, cell migration was decreased. Although evidence for EMT-inhibitory effects of salinomycin exists (16), other literature also confirms the current data suggesting that escalating doses of salinomycin correlate with an upregulation of vimentin and downregulation of E-cadherin (27). These findings may be explained by a possible non-correspondence between EMT and certain cell abilities, such as invasion, in these cell lines (27). In EMT-transformed A549 cells treated with salinomycin, the present investigations of protein expression and migration revealed different results compared to those for HCC4006 cells. Although cell migration in A549 cells is more strongly inhibited by the higher dose of salinomycin, both vimentin and E-cadherin are upregulated. This divergent effect in the two cell lines may have two explanations. Firstly, salinomycin may inhibit cell migration and influence TGF $\beta$-related EMT by interfering with different signalling pathways. Alternatively, established epithelial and mesenchymal markers like E-cadherin and vimentin may not be adequate to analyze the effects of salinomycin on EMT-transformed cells. Further studies must be performed to elucidate the exact mechanisms of salinomycin treatment on EMT.

In summary, the present study provides evidence that metformin and salinomycin have the potential to specifically block TGF $\beta$-induced EMT in NSCLC and inhibit EMT-induced cell migration in NSCLC cell lines. To the best of our knowledge, these results highlight for the first time that these two substances are effective EMT-inhibiting agents in NSCLC. To what extent such strategies may be transferred to the clinic remains to be analyzed in further investigations.

\section{References}

1. Iwatsuki M, Mimori K, Yokobori T, Ishi H, Beppu T, Nakamori S, Baba $\mathrm{H}$ and Mori M: Epithelial-mesenchymal transition in cancer development and its clinical significance. Cancer Sci 101: 293-299, 2010.

2. Tsai JH and Yang J: Epithelial-mesenchymal plasticity in carcinoma metastasis. Genes Dev 27: 2192-2206, 2013.

3. Thiery JP and Sleeman JP: Complex networks orchestrate epithelial-mesenchymal transitions. Nat Rev Mol Cell Biol 7: 131-142, 2006.

4. Medici D, Hay ED and Olsen BR: Snail and Slug promote epithelial-mesenchymal transition through beta-catenin-T-cell factor-4-dependent expression of transforming growth factor-beta3. Mol Biol Cell 19: 4875-4887, 2008.

5. Xu J, Lamouille S and Derynck R: TGF-beta-induced epithelial to mesenchymal transition. Cell Res 19: 156-172, 2009.

6. Moustakas A: Smad signalling network. J Cell Sci 115: 3355-3356, 2002

7. Dowling RJ, Niraula S, Stambolic V and Goodwin PJ: Metformin in cancer: Translational challenges. J Mol Endocrinol 48: R31-R43, 2012.

8. Evans JM, Donnelly LA, Emslie-Smith AM, Alessi DR and Morris AD: Metformin and reduced risk of cancer in diabetic patients. BMJ 330: 1304-1305, 2005.

9. Kourelis TV and Siegel RD: Metformin and cancer: New applications for an old drug. Med Oncol 29: 1314-1327, 2012.

10. Cufi S, Vazquez-Martin A, Oliveras-Ferraros C, Martin-Castillo B, Joven J and Menendez JA: Metformin against TGF $\beta$-induced epithelial-to-mesenchymal transition (EMT): From cancer stem cells to aging-associated fibrosis. Cell Cycle 9: 4461-4468, 2010.

11. Tan BK, Adya R, Chen J, Lehnert H, Sant Cassia LJ and Randeva HS: Metformin treatment exerts antiinvasive and antimetastatic effects in human endometrial carcinoma cells. J Clin Endocrinol Metab 96: 808-816, 2011.

12. Naujokat C, Fuchs D and Opelz G: Salinomycin in cancer: A new mission for an old agent. Mol Med Rep 3: 555-559, 2010.

13. Bardsley MR, Horváth VJ, Asuzu DT, Lorincz A, Redelman D, Hayashi Y, Popko LN, Young DL, Lomberk GA, Urrutia RA, et al: Kitlow stem cells cause resistance to Kit/platelet-derived growth factor alpha inhibitors in murine gastrointestinal stromal tumors. Gastroenterology 139: 942-952, 2010.

14. Fuchs D, Daniel V, Sadeghi M, Opelz G and Naujokat C: Salinomycin overcomes ABC transporter-mediated multidrug and apoptosis resistance in human leukemia stem cell-like KG-1a cells. Biochem Biophys Res Commun 394: 1098-1104, 2010.

15. Fuchs D, Heinold A, Opelz G, Daniel V and Naujokat C: Salinomycin induces apoptosis and overcomes apoptosis resistance in human cancer cells. Biochem Biophys Res Commun 390: 743-749, 2009.

16. Gupta PB, Onder TT, Jiang G, Tao K, Kuperwasser C, Weinberg RA and Lander ES: Identification of selective inhibitors of cancer stem cells by high-throughput screening. Cell 138: 645-659, 2009. 
17. Ketola K, Hilvo M, Hyötyläinen T, Vuoristo A, Ruskeepää AL, Orešič M, Kallioniemi O and Iljin K: Salinomycin inhibits prostate cancer growth and migration via induction of oxidative stress. Br J Cancer 106: 99-106, 2012.

18. Liang CC, Park AY and Guan JL: In vitro scratch assay: A convenient and inexpensive method for analysis of cell migration in vitro. Nat Protoc 2: 329-333, 2007.

19. De Craene B and Berx G: Regulatory networks defining EMT during cancer initiation and progression. Nat Rev Cancer 13: 97-110, 2013

20. Larue L and Bellacosa A: Epithelial-mesenchymal transition in development and cancer: Role of phosphatidylinositol 3 kinase/AKT pathways. Oncogene 24: 7443-7454, 2005.

21. Kuwahara F, Kai H, Tokuda K, Kai M, Takeshita A, Egashira K and Imaizumi T: Transforming growth factor-beta function blocking prevents myocardial fibrosis and diastolic dysfunction in pressure-overloaded rats. Circulation 106: 130-135, 2002.

22. Willis BC and Borok Z: TGF-beta-induced EMT: Mechanisms and implications for fibrotic lung disease. Am J Physiol Lung Cell Mol Physiol 293: L525-L534, 2007.
23. Heldin $\mathrm{CH}$, Vanlandewijck $\mathrm{M}$ and Moustakas A: Regulation of EMT by TGF $\beta$ in cancer. FEBS Lett 586: 1959-1970, 2012.

24. Massagué J: TGFbeta in cancer. Cell 134: 215-230, 2008.

25. Vazquez-Martin A, Oliveras-Ferraros C, Cufi S, Del Barco S, Martin-Castillo B and Menendez JA: Metformin regulates breast cancer stem cell ontogeny by transcriptional regulation of the epithelial-mesenchymal transition (EMT) status. Cell Cycle 9: 3807-3814, 2010

26. Zhao Z, Cheng X, Wang Y, Han R, Li L, Xiang T, He L, Long $\mathrm{H}$, Zhu B and He Y: Metformin inhibits the IL-6-induced epithelial-mesenchymal transition and lung adenocarcinoma growth and metastasis. PloS One 9: e95884, 2014.

27. Kuo SZ, Blair KJ, Rahimy E, Kiang A, Abhold E, Fan JB, Wang-Rodriguez J, Altuna X and Ongkeko WM: Salinomycin induces cell death and differentiation in head and neck squamous cell carcinoma stem cells despite activation of epithelial-mesenchymal transition and Akt. BMC Cancer 12: $556,2012$. 